ANADOLU, J. of AARI

ISSN: 1300-0225 (Print)

E-ISSN: 2667-6087 (Online)

2019, 29 (2): 177-187

DOI: $10.18615 /$ anadolu. 660198

\title{
Tarımsal Kooperatiflerin Dünya ve Türkiye’de Mevcut Durumunun Karşılaştırılması
}

\author{
Bekir PAKDEMIRLI* \\ T.C. Tarım ve Orman Bakanlı̆ğ, Ankara / TURKEY \\ *https://orcid.org/0000-0002-0336-0613 \\ *Corresponding author (Sorumlu yazar): bekir@pakdemirli.com \\ Received (Geliş tarihi): 15.11.2019Ａccepted (Kabul tarihi): 28.11.2019
}

\begin{abstract}
ÖZ: Kooperatifler, kırsal kalkınmada, kıt kaynaklara sahip olan üreticilerin verim ve gelirlerini artırmada, tarımsal gelişmeyi sürdürülebilir hale getirmede önemli araçlardan biri olup, gelişmiş ve gelişmekte olan ülkelerde etkin bir biçimde kullanılmaktadır. Küçük ölçekli üreticiler, dezavantajlı yapıları nedeni ile çağdaş tarım piyasalarına adapte olurken birçok zorlukla karșı karșıya kalmaktadır. Ancak, kooperatifler üreticilerin bu zorluklarla başa çıkmalarına yardımcı olan kurumsal yapılar olarak karşımıza çıkmaktadır. Ülkemizde başlangıcı 1863 yılına dayanan modern kooperatif̧̧ilik, Cumhuriyet Döneminde Atatürk'ün önderliğinde yapılan yasal düzenlemelerle, ön plana çıkmıs, planlı kalkınma döneminde verilen devlet desteği ve yönlendirmesi ile önemini korumuştur. Bununla birlikte, bir takım yapısal sorunlarla karşı karşıya olan ülkemiz tarımsal kooperatif̧̧iliği günümüzde istenilen düzeye ulaşamamıştır. Bu çalışma, dünyada ve Türkiye'de kooperatifçiliğin tarihsel gelişimini ve yapısını ortaya koyarak, mevcut durumu karşılaştırarak ve kooperatiflerin tarımsal ekonomideki rolünü irdeleyerek ülkemizdeki kooperatifçiliğin gelişimine katkı sağlamayı amaçlamaktadır.
\end{abstract}

Anahtar Kelimeler: Tarımsal kooperatifler, tarımsal kalkınma, Türkiye, dünya.

\section{Comparison of the Current Situation of Agricultural Cooperatives in the World and Turkey}

ABSTRACT: Cooperatives, one of the important tools helping rural development, increasing producers' yields and incomes that have scarce resources, and making sustainable agricultural development, are used effectively in developed countries and emerging countries. Due to their disadvantageous structure, small-scale producers face many difficulties in adapting to contemporary agricultural markets. However, cooperatives emerge as institutional structures that help producers to cope with these challenges. The modern cooperative system in our country, whose origin dates back to 1863, has been prominent in the Republican Era with the legal arrangements made under the leadership of Atatürk, and maintains its importance with the state support and guidance given during the planned development period. Nevertheless, agricultural cooperatives of our country, which are facing a number of structural problems, have not reached the desired level today. This study aims to contribute to the development of our country's cooperatives by revealing the historical development and structure of cooperatives, comparing the current situation and examining the role of cooperatives in the agricultural economy of the world and Turkey.

Keywords: Agricultural cooperatives, agricultural development, Turkey, world.

\section{GíRiș}

Küçük toprak sahibi çiftçiler yeni gıda piyasalarına adapte olurken birçok zorlukla karşı karşıya kalmaktadır. Bu zorluklar temel olarak küçük çiftçilerin piyasalardaki dezavantajlı durumlarıyla ilişkilidir. Alıcılar belirli bir kalitede ürün satın alırken, bilgi toplama ve ürün arama maliyetlerinden tasarruf sağlamak isterler ve bireysel çiftçiler tarafından gerçekleştirilen küçük 
çaplı işlemleri dışlarlar (Sauer ve ark., 2012). Küçük çiftçilerin yaşadığı başka bir zorluk da asimetrik bilgidir. Uygun pazar bilgisinin eksikliği, çiftçilerin kalite ve diğer gereksinimlere uymalarını zorlaştırmakta ve onları değer zincirindeki diğer unsurlara nazaran zayıf bir pazarlık pozisyonuna sokmaktadır.

Bir kooperatifin, çiftçilere yukarıda açıklanan zorluklarla başa çıkmalarında yardımcı olabilecek kurumsal bir araç olduğu düşünülmektedir. Kooperatifler, çiftçilerin hem girdi hem de çıtı piyasalarında pazarlık gücünü artırabilmekte (Fischer ve Qaim, 2012) ve çiftçiler ile piyasa arasındaki bilgi akışını kolaylaştırabilmektedir (Mojo ve ark., 2017). Kooperatifler diğer piyasa kurumları ile karşılaştırıldığında, genel olarak küçük toprak sahiplerini içerirler (Verhofstadt ve Maertens, 2014). Bu özellikleri ile kooperatifler, küçük çiftçilerin pazardaki konumunu güçlendirerek, yoksulluğun azaltılmasına ve kırsal kalkınmaya katkıda bulunurlar (Bernard ve Spielman, 2009).

Kooperatiflerin potansiyel rolü iki önemli yapısal sorunla karşı karşıya olan Türk tarımı ile özellikle ilgilidir. İlk sorun, arazi parçalanması ve işletme ölçeğinin küçük olması koşullarında modern tarımın nasıl geliştirileceğidir (Demirtaş ve Sarı, 2016). Arazi parçalanması verimlilik azalışı ve sonuç olarak üretim azalması anlamına gelmektedir. Diğer bir zorluk da küçük toprak sahibi çiftçilerin tarım-gıda pazarlarındaki yapısal değişikliklerle nasıl başa çıkabileceği ve değişen pazar ortamında nasıl fayda sağlayabileceği ile ilgilidir.

Tüketicilerin artan satın alma gücündeki iyileşme ve gida güvenliği kontrolündeki teknik gelişmeler nedeniyle, daha kaliteli ve daha sık1 güvenlik standartlarına sahip gida talebi artmaktadır (Narrod ve ark., 2009). Ayrıca, süpermarketlerin büyümesi ve uluslararası ticaretin yaygınlaşması ile, yüksek kaliteli g1daların uluslararası ticaretteki payı artmakta ve tüketim kalıpları değişmektedir (Tran ve ark., 2013). Bu nedenlerden ötürü, tarım-gıda piyasaları büyük yapısal değişiklikler yaşamaktadır. $\mathrm{Bu}$ değişiklikler, küçük toprak sahipleri için hem firsatlar hem de zorluklar yaratmaktadır. Kooperatifler, çiftçilerin; ihracat pazarlarından, yerel süpermarketlerden ve yeni tür üretim yapan firmalardan kaynaklanan firsatları değerlendirmelerini sağlamakta (Bijman, 2016), fakat bununla beraber çiftçilerin daha katı üretim ve güvenlik standartlarına uymaları, değer zincirinde birbirini takip eden faaliyetlerin koordinasyonunu daha iyi sağlamaları ve yüksek kalitede ürünler üretmeleri gerekmektedir (Fritz ve Schiefer, 2008; Reardon ve ark., 2009; Abebe ve ark., 2013). Kooperatifler bu şartlara uyum sağlamada önemli rol üstlenirler.

Bu çalışma, dünyada ve Türkiye'de kooperatifçiliğin tarihsel gelişimini ve yapısını ortaya koyarak ve kooperatiflerin tarımsal ekonomideki rolünü irdeleyerek, ülkemizdeki kooperatifçiliğin gelişimine katkı sağlamayı amaçlamaktadır.

\section{KOOPERATIFLERIN GELIŞSIMİ ve YAPILARI}

\section{Kooperatiflerin Tarihçesi}

\section{Dünyada kooperatiflerin tarihçesi}

Avrupa kooperatiflerinin tarihi 19. yüzyllın ortalarına kadar uzanmaktadır. Ayrıca Kuzey Amerika ve Okyanusya'da kooperatifler yine 19. yüzyılın ikinci yarısında ortaya çıkmıştır (Fernández, 2014). 1844'te Büyük Britanya'da kurulan "Rochdale Equited For Equioneers" derneği gıda maliyetlerini düşürerek ve istihdam ve eğitim firsatlarını artırarak, üyelerinin yaşam koşullarını iyileştirmeyi amaçlamaktaydı. Almanya'da ise kooperatiflerin gelişiminde önemli bir dönüm noktası olarak kabul edilen Raiffeisen Bankası 1864 yılında kurulmuştur. Raiffeisen'in birincil amacı, "kendi kendine yardım" fikrine dayanarak kırsal alanlarda tasarruf ve kredi hizmetleri sağlamaktı.

Danimarka kooperatiflerinin 1880'lerde kurulması, hem ucuz ithal tahilla hem de tarife korumasinin azalmasıyla yakından bağlantılıydı (Gutierrez ve Carlos, 2005). Benzer șekilde, Fransa ve Hollanda'da kooperatiflerin faaliyete geçmesi, çiftçilerin 19. yüzyılın sonlarında yaşanan tarımsal ekonomideki krize yanıtı olarak gösterilebilir. 1877'de, Hollanda'daki çiftçiler, kaliteli kimyasal gübre satın almak için ilk kooperatiflerini kurmuşlardır (Gutierrez ve Carlos, 2005). 1880'lerde ise Fransız çiftçiler, aracıların pazar hâkimiyetine karşı koymak amaciyla ortak gübre alımları için bir sendika altında toplanmışlardır (Dedieu ve Courleux, 2011). Chloupkova (2002)'ya göre, AB ülkelerinde çiftçilerin 
kooperatif kurmalarının en önemli nedeni, küçük toprak sahibi çiftçilerin karşılaştıkları ekonomik zorluklard1. Pazarlık gücündeki dengesizlik nedeniyle, tarım üreticileri ekonomik koşullarını iyileştirmek ve piyasa başarısızlıklarının negatif etkilerini azaltmak için kurumsal yapılanmaya ihtiyaç duymuşlardır.

Kooperatiflerde üst örgütlenme, bir ülkede kooperatiflerin, birim kooperatiften ulusal birliğe kadar dikey olarak örgütlenmesidir (Mülayim, 1995). Kooperatif üst örgütlerinin kurulması hem devlet politikalarını etkilemek hem de bölgesel ve ulusal düzeyde ortak işletmeler kurmak suretiyle yerel kooperatiflerin gelişimini desteklemiştir. Bireyler, tek başlarına yapamayacakları veya birlikte yapmalarında yarar bulunan işleri en iyi bir biçimde ve en az maliyetle yapmak üzere ekonomik güçlerini bir araya getirerek birim kooperatifleri; aynı amaçla, birim kooperatifler de güçlerini bir araya getirerek birim üstü kooperatifleri (kooperatifler birliği, merkez birliği, ulusal birliği) oluşmaktadır (Mülayim, 1995). Finlandiya tarım kooperatiflerinin tarihsel gelişimi ve sahip oldukları refah seviyesi bu iddiay1 desteklemektedir. Çiftçilerin her zaman bir iş birliği geleneğine sahip olduğu Finlandiya'da, merkezi bir kuruluş olan Pellervo Society'nin (Finlandiya Pellervo Kooperatifleri) kurulmasindan sonra kooperatiflerde hızlı bir büyüme yaşanmıştır (Anonymous, 2019a). Tarımsal kooperatifler, Finlandiya tarım sektöründe, 20. yüzyılın başlarından bu yana, çoğu gıda ürününde pazarın yarısından fazlasına hâkim olarak, önemli bir rol oynamaktadır (Bijman ve ark., 2012).

\section{Türkiye'de kooperatiflerin tarihçesi}

Türkiye'de çağdaş kooperatifçiliğin ilk uygulamasının kamu eliyle 1863 yılında kurulan "memleket sandıkları" olduğu kabul edilmektedir. Memleket sandıklarının temel amacı, çiftçilerin kredi alanında karşılaştıkları zorlukları aşmak olmuştur (Can ve Sakarya, 2012). Bu sandıklar daha sonra yerlerini, 1888 y1lında kurulan Ziraat Bankası'na bırakmıştır. 1913 yılında kurulan Aydın İncir Müstahsilleri Kredi ve Satış Kooperatifi, Türkiye'nin ilk tarım satış kooperatifidir. Cumhuriyet Döneminde Atatürk'ün önderliğinde kooperatiflere yönelik yapılan yasal düzenlemelerle, bu örgütlenme türü daha fazla ön plana çıkmıştır. İtibarî Ziraî
Birlikleri Kanunu bu kapsamda 1924 tarihinde yürürlüğe girmiştir (Öksüz, 1982). Bu kanunu sirasiyla, 1929 yılında Zirai Kooperatifler Kanunu ve 1935 yılında Tarım Satış ve Tarım Kredi Kooperatifleri Kanunları izlemiștir (Bilgin ve Tanıyıc1, 2008). Söz konusu yasal düzenlemeler tarımsal üreticilerin karşılaştığı zorlukların çözümünde Mustafa Kemal Atatürk'ün kooperatif örgütlenmeye büyük önem verdiğini ve devlet yönetiminin kooperatifçiliğin gelişiminde belirleyici bir rol oynadığını göstermektedir (Can ve Sakarya, 2012). Sonraki y1llarda ihracat ürünlerinde örgütlenmeye gidilmesini hedefleyen devlet, 1936 yılında Ĭgdır, Ege ve Trakya'da çeşitli kooperatiflerin kurulmasını sağlamış, bu örnekleri Karadeniz bölgesinde kurulan diğer kooperatifler izlemiştir (Örki, 2016).

Planlı kalkınma döneminde de kooperatifçilik kavramına önem verilmeye devam edilmiştir. 1961 Anayasa'sının 51. maddesinde: "Devlet, kooperatifçiliğin gelişmesini sağlayacak tedbirleri alır" ifadesine yer verilerek kooperatifçiliğin gelişiminde devlet daha sorumlu hale getirilmiştir. 1163 say1l Kooperatifler Kanunu (1969), 1581 sayılı Tarım Kredi Kooperatifleri ve Birlikleri Kanunu (1972) ve 4572 sayılı Tarım Satış Kooperatif ve Birlikleri Hakkında Kanun (2000), kooperatiflere yönelik devlet desteği ve yönlendirmesinin dönem boyunca devam ettiğini göstermektedir (Can ve Sakarya, 2012). Buna paralel, Birinci Beş Yıllık Kalkınma Planı'ndan (1963-1967) itibaren bütün planlarda kooperatiflere yer verilmiştir (Alkan, 1998). Nitekim, son olarak 2019-2023 yıllarını kapsayan On Birinci Kalkınma Planı da öncelikli gelişme alanlarından biri olan tarımda, kooperatifçiliğe devlet desteğinin süreceğini öngörmektedir. On Birinci Kalkınma Planı'nın 413. ve 451. maddeleri hem pazarlama hem de üretim süreçlerinde üreticilere kooperatifler aracılığı ile kalkınma desteği sunulacağını belirtmektedir (Anonim, 2019a).

\section{Kooperatiflerin Yasal Dayanağı}

Kooperatiflerin Avrupa'da uzun bir geçmişi vardır. Çoğu AB ülkesi, özellikle Batı ve Kuzey Avrupa ülkeleri, bir asırdan fazla bir süre önce kooperatif kanunları oluşturmuşlardır. $\mathrm{Bu}$ kanunlar kooperatiflerin gelişmesini teşvik etmiş ve yasal reformlar kooperatif gelişimi ile el ele ilerlemiştir (Fici, 2013). Kooperatif yasaları, ülkeler bazında 
birtakım farklılıklar gösterse de daha ziyade benzerlikler ön plana çıkmaktadır. Hollanda'daki kooperatifler hakkındaki mevzuat Kuzey-Bat Avrupa'daki kooperatif kalkınmasının bir örneği olarak düşünülebilir. Dolayısıyla, Türkiye ve Avrupa kooperatifleri arasındaki yasal statü farklılıkları üzerinde dururken Hollanda ve Türkiye kooperatif kanunları karşılaştırılabilir.

Hollanda Kooperatif Kanunu, kooperatifi şöyle tanımlar: "Kooperatif tüzel bir kişidir. En az iki müessis tarafindan kurulur ve kuruluşta iki veya daha fazla üyesi olması gerekir. Bu ilk üyelerden en az ikisi kooperatifin kurucusu olmalıdır. Kuruluşundan sonra ise kooperatifin tek bir üyesi olabilir. Kooperatifin adı "coöperatief" veya "coöperatie" kelimesini içermelidir. Hem gerçek kişiler hem de tüzel kişiler bir kooperatif üyesi olabilir". Türkiye'de 1163 sayılı Kooperatifler Kanunu'nun birinci maddesine göre ise kooperatif: "Tüzel kişiliği haiz olmak üzere ortaklarının belirli ekonomik menfaatlerini ve özellikle meslek veya geçimlerine ait ihtiyaçlarını işgücü ve parasal katkılarıyla karşılıklı yardım, dayanışma ve kefalet suretiyle sağlayıp korumak amacıyla gerçek ve tüzel kişiler tarafindan kurulan değişir ortaklı ve değişir sermayeli ortaklıklara kooperatif denir" şeklinde tanımlanmıştır. Kanunun ikinci maddesine göre ise: "Bir kooperatif en az 7 ortak tarafindan imzalanacak ana sözleşme ile kurulur. Kooperatif adını ancak bu kanuna göre kurulmuş teşekküller kullanabilir".

Finansman ve kâr dağıtım kuralları Hollanda kooperatifleri için kanunda açıkça belirtilmiştir. "Kooperatif için yasal minimum sermaye zorunluluğu yoktur. Üyeler kooperatife borç ya da sermaye olarak fon sağlayabilirler, ancak bu zorunlu değildir. Kooperatifin kazancı sermaye hesabına veya yedek hesaba eklenebilir veya doğrudan üyelere dağıtılabilir. $\mathrm{Bu}$ ekleme veya dağıtım üyelerin katkı payına bakılmaksızın yapılabilir". Türkiye Kooperatifler Kanunu sermaye için Hollanda kooperatifleri ile benzerlik göstermektedir. Fakat kâr dağıtımı ile ilgili şu hükümler bulunmaktadır: "Gelir-gider farkının en az $\% 10$ 'u yedek akçeye, kooperatif üst kuruluşlarında ise buna ilaveten en az \%5'i fevkalade yedek akçeye ayrılmadıkça ortaklara dağıtım yapılmaz. Gelir-gider farkının ortaklar arasında bölüşülmesi öngörülmüş ise bu bölünme ortakların muameleleri oranında yapılır". Hollanda ve Türkiye kooperatif kanunları ile ilgili diğer bir ortak nokta ise ortakların oy hakkıdır. Kanunda belirtilen şekli ile:" Genel Kurulda her ortak yalnız bir oya sahiptir". Ortaklık yapısında homojenlik açısından eşit oy hakkı önem taşımaktadır.

Genel olarak bakıldığı zaman kuruluş, kâr dağıtımı ve oy hakk1 hükümlerinde küçük farklılıklar olmasına rağmen, Türkiye ve Avrupa kooperatifleri kanuni düzeyde benzerlik göstermektedir.

\section{Kooperatif Finansmanı}

Finansman bir kooperatifin başarısı için çok önemlidir. Üç temel kooperatif ilkesi; ortak mülkiyet, ortak kontrol ve ortak yarar, birbirlerine üyelerin finansal payları ile bağlanmaktadır (Dunn, 1988). Üyelerin kooperatiflere maddi katk1larını sürdürememeleri kooperatifin varlığını tehlikeye atabilir. Özellikle kooperatifin kurulum aşamasında üye katkıları çok önemlidir, ancak aynı zamanda zordur. Bhuyan ve Leistritz'in (2001), yaptığ araştırmaya göre, başlangıç aşamasında bir kooperatif için en önemli sorunlar arasında öz kaynak sermayesi ve borç (yabancı kaynak) sermayesi sirasiyla birinci ve ikinci sirada yer almaktadır.

Avrupa ve Kuzey Amerika'da, kooperatiflerin üç ana sermaye kaynağı vardır. Birincisi, üyeler üyelik ücreti ödeyerek katkıda bulunurlar. İkincisi, üyeler üyelik hisselerini satın alırlar. Üçüncüsü ise, üyeler yatırım hisseleri satın alırlar. Ancak, kooperatif için en önemli sermaye kaynağ1 dağıtılmayan kârlardır. Bu, bir kooperatifin gelirgider farkının tamamını üyelerine dağıtmadığ bunun bir kısmını yedek akçeye eklediği anlamına gelir. Dağıtılmayan kazanç yüzdesi kooperatiften kooperatife farkl1l1k gösterebilir. Öz sermaye kaynaklarına ek olarak, kooperatifler borçlanarak da sermaye yükseltebilir. Borç sermayesi, belirtilen faiz oranları, şartlar ve koşullar altında geri ödemek kaydıyla, yasal bir yükümlülükle ödünç alınan paradır. Tarımsal kooperatifler, diğer tür işletmelerle aynı borç sermayesi kaynaklarının çoğunu kullanmakla beraber, daha yaygın olarak kooperatif bankalarından borçlanırlar.

Rekabetin çok yoğun olduğu piyasalarda faaliyet gösteren pazarlama kooperatifleri, çoğu zaman, üyelerinin katkıda bulunabileceği veya katkıda 
bulunmaya istekli olduğundan daha fazla öz sermayeye ihtiyaç duyarlar. Bir kooperatifin ek sermaye elde etmeden büyümesi için kullanılan klasik stratejilerden biri, başka bir kooperatif ile birleşmektir (Richards ve Manfredo, 2003). Birleşmeler cazip değilse ve üyeler daha fazla sermayeye katkıda bulunamıorsa, diş yatırımcılar da bir seçenek olabilir (Chaddad ve Cook, 2004). Örneğin, Hollanda ve Finlandiya'da kooperatif kanunu dışarıdan sermaye yatırımına izin vermektedir (Brusselaers ve ark., 2014).

1163 sayıl1 Kooperatifler Kanunu'nun 19. Maddesi'ne göre: "Kooperatife giren her şahıstan en az bir ortaklık payı alınması gerekir. Bir ortaklık payının değeri 100.000 liradır. Kooperatife giren ortaklar en çok 5000 pay taahhüt edebilirler". Dolayısıyla Türkiye'de kooperatiflerin sermayesi, ortaklarının taahhüt ettikleri ortaklık paylarından oluşmaktadır. Finansmana erişim, Türk kooperatiflerinin gelişimi için en büyük zorluk olarak görülmektedir. Çünkü küçük ölçekli üyelerin genellikle kooperatiflerine yatırım yapacak sermayeleri yetersizdir.

Kendilerine özgü özellikleri nedeniyle kooperatiflerin finansal sorunları normal bir işletmenin sorunlarından daha çeşitli ve ciddidir. Bilhassa, temelde kâr amacı güdülmemesi nedeniyle alıkonulan kârların büyük önem arz etmemesi, ortaklar tarafından yapılan sermaye katkısının sınırl kalması ve tahvil ve hisse senedi gibi finansal varlıklar yoluyla kaynak temin edilememesi bu özelliklerin başında gelmektedir. Ayrıca, güçlü bir yapıya sahip olmayan kooperatiflerin kredi kurumlarından yeterince teminat gösteremedikleri için kredi sağlamaları da imkânsız olmaktadır (Anonim, 2012). Kooperatifler Kanunu'nun 19. maddesi: "Tarımsal amaçlı kooperatiflerin yatırım faaliyetleri, ilgili bakanlıkça düzenlenen yönetmelik esasları dahilinde, bütçeden ayrılacak ödenekler yoluyla verilecek düşük faizli kredilerle desteklenir" hükmünü içermektedir. Sermaye yetersizliği sorunu olan kooperatifler için devlet desteği bu bağlamda önemlidir. Finansmana erişimi kolaylaştırma amacinda olan Kredi Garanti Fonu da bu kapsamda inşaat, arsa, yapı kooperatifleri hariç olmak üzere birlikler ve birliklere bağlı kooperatiflere kefalet desteği sağlamaktadır (Anonim, 2019b).

\section{Kooperatif Yönetimi}

Bir kooperatifin yönetimi, üyelerin kooperatifin stratejilerini ve politikalarını nasıl belirledikleri ile ilgilidir. Kooperatifler değişen piyasa koşulları, politikalar ve teknoloji yapısına sahip olan dinamik bir ortamda faaliyet gösterdiklerinden dolay1, yönetimlerini değişen koşullara adapte edebilmeleri önemlidir (Mooney, 2004).

Genel olarak, Avrupa kooperatif yönetiminin geleneksel modeli, Kuzey Avrupa modeli ve Güney Avrupa modeli olarak gelişmiştir (Chaddad ve Iliopoulos, 2013). Geleneksel model, kooperatif kanunu ile zorunlu tutulan Genel Kurul (GK) ve Yönetim Kurulu'ndan (YK) ve bir Denetleme Kurulundan (DK) oluşur. Kuzey Avrupa'da, geleneksel model farklı üç modele dönüşmüştür: genişletilmiş geleneksel model, yönetimsel model ve kurumsal model (Bijman ve ark., 2013). Öte yandan, Güney Avrupa'daki kooperatiflerin yönetiminde baskin modeller, geleneksel ve genişletilmiş geleneksel modellerdir (Rebelo ve ark., 2008).

Bahsedilen bu modellerin yapıları şu şekilde özetlenebilir. Genişletilmiş geleneksel model, kooperatif girişimini yöneten profesyoneller içermektedir. Kooperatiflerin artan ölçeği ve karmaşıklığ 1 ve pazara yönelik stratejileri ile kooperatifler, yönetim kurulunun yürütme görevleri için günümüzde daha çok profesyonel yöneticiler kullanırlar (Bijman ve ark., 2014). Yönetim modeli, yalnızca profesyonel yöneticilerin yönetim faaliyetlerini yürütmek için Yönetim Kurulu'nu oluşturması ile, YK'y1 ve profesyonel yönetimi birleştirir. Kurumsal model ise, DK'yi YK ile birleştirir ve karar haklarının çoğunun profesyonel yöneticilere devredildiği ve yönetim kurulunun yalnızca kontrolden sorumlu olduğu genişletilmiş bir YK oluşturur (Chaddad ve Iliopoulos, 2013).

Türk tarım kooperatiflerinin çoğunluğu, genel kurul, bir yönetim kurulu ve bir denetim kurulundan oluşan geleneksel batı kooperatifleri ile benzer bir temel yönetim yapısına sahiptir. Kooperatif yöneticileri yasa gereği genel kurulda seçilirler. Bunun dışında yönetim kurulu üyeliği için herhangi başka şart aranmaz. Türk kooperatiflerinde genel olarak yönetim kuruluna seçilen yöneticiler, kooperatifçilik ve yönetim konularında herhangi 
bir eğitim almamış olan kişilerdir. Ölçek küçüklüğü, profesyonel yönetici ve uzman personel istihdamı sağlayamayan kooperatifleri, başarılı olma yönünde negatif etkileyen faktörlerden biridir. Halbuki kooperatifler de dahil bir işletmenin başarılı olabilmesi için kurumsal yönetim ilkeleri çerçevesinde yönetilmesi gerekir. Türk kooperatifçiliğinin gelişimi ile yakından ilgili olan bir diğer konu da kooperatiflerde denetim sorunudur. Denetim kurulu üyeleri, genellikle uzman olmayan kişilerden oluşmakta ve kanun ve ana sözleşmeden kaynaklanan görev ve sorumluluklarını yeterince bilememekte veya yerine getirmemektedir.

Sonuç olarak, Türk kooperatifleri geleneksel yönetim modelini takip ederken, Kuzey ve Güney Avrupa kooperatifleri geleneksel yönetim modellerinde bir değişime uğramışlardır. Avrupa kooperatiflerinin karar alma hakları, kademeli olarak üyelerden profesyonel yönetimlere geçmektedir. Öte yandan, Türk kooperatiflerinde genellikle profesyonel yönetici istihdam edilmemektedir ve karar hakları çoğunlukla üyelere aittir (Anonim, 2012).

\section{Kooperatif - Devlet İlişkileri}

Devletler kooperatiflerin geliştirilmesinde önemli bir rol oynamakta ve dış destek olarak görülmektedir. Kooperatif faaliyetlerinden katk1 ödemeden faydalanma sorunu, deneyim eksikliği, potansiyel üyelerin düşük güven duygusu ve yüksek organizasyon maliyetleri nedeniyle, çiftçilerin dış destek olmadan yeni bir kooperatif kurmaları oldukça zordur (Ostrom, 1990; Fairbairn, 2004).

Iliopoulos (2013)'a göre, kamu desteği farklı şekillerde görülür: (1) kooperatiflere karşı hiçbir şekilde ayrımcılık yapılmayan yasal bir çerçeve sağlanmasi; (2) anti-tröst yasa ve düzenlemelerinden muafiyet; (3) destekleyici vergi düzenlemesi; (4) uygun kredi koşullarına erişim ve (5) teknik yardım. Tarımsal kooperatifleri destekleyen politikaların yoğunluğu ve içeriği ülkeden ülkeye önemli ölçüde değişiklik göstermektedir (Iliopoulos, 2013).

Türkiye'de kooperatifçiliğin geçmişine bakıldığında; devletin öncülüğü ya da devletin verdiği teşviklerin kooperatiflerin gelişmesinde önemli rol oynadığı görülmektedir (Bilgin ve Tanıyıc1, 2008). Özellikle, destekleme alımlarının kooperatifler aracılığıyla yapılması, kooperatiflere bazı alanlarda imtiyazlar sağlanması, kredilendirme işlemlerinin kooperatifler üzerinden yapılması gibi birtakım uygulamalar, kooperatiflerin sayılarının artmasına neden olmuştur (Bilgin ve Tanıyıc1, 2008). Diğer bir deyişle, kooperatifler devlet sayesinde büyümüş ve sayıca artmıştır. Öte yandan devlet destekleri, kooperatifleri yönetimsel olarak devlete bağımlı hale getirmiştir. $\mathrm{Bu}$ durum kooperatifçiliğin fonksiyonlarını ve etkinliğini olumsuz etkileyen bir hal almıştır (Alkan, 1998).

Dünyadaki kooperatif destek uygulamalarında ise aşağıdaki ilkeler gözetilmektedir (Anonim, 2012);

i) destek verilecek kooperatiflerin finansal ve yönetimsel bağımsızlıklarının korunması,

ii) kooperatiflerin faaliyetlerinin sürdürülebilirliğinin birinci planda olmas1,

iii) faaliyetlerini sürdürürken devlet desteğine bağımlı hale gelmemesi,

iv) verilen desteklerin kamu kaynaklı ana sermaye veya başlangıç desteği şeklinde olması

v) destek verilen kooperatiflerin sosyal amaçlı olsalar dahi kâr amacı gütmelerinin esas olması.

\section{KOOPERATIFLERİN TARIMSAL EKONOMIDEKİ YERİ}

Kooperatifler küçük toprak sahiplerinin üye olduğu ve bu çiftçilerin pazarda yer edinmesi sağlayan kuruluşlardır (Verhofstadt ve Maertens, 2014). Kooperatifler bu yönleriyle gelir dağılımına, yoksulluğun azaltılmasına ve kırsal kalkınmaya katkı sağlarlar (Bernard ve Spielman, 2009). Dünya nüfusunun en az \%12'si, sayısı yaklaşık 3 milyonu bulan kooperatiflerden birine üyedir. Kooperatifler, dünya genelinde 280 milyon kişiye, diğer bir deyişle dünyada çalışan nüfusun \%10'una istikrarlı ve kaliteli istihdam sağlayarak sürdürülebilir ekonomik büyümeye katkıda bulunurlar (Anonymous, 2019b)

\section{Dünyada Kooperatif Ekonomisinin Mevcut Durumu}

Tarımsal kooperatifler tüm dünyada zaman içerisinde büyüyerek uluslararası piyasada yer edinen, başarılı ekonomik kuruluşlar haline gelmişlerdir. International Cooperative Alliance (Uluslararası Kooperatifler Birliği, ICA) 
kooperatiflerin önemini vurgulamak ve ülke ekonomilerine yaptıkları katkıları göstermek amacıyla "Top-300" başlıklı bir proje yürütmektedir. ICA ve Euricse (Anonymous, 2019c) tarafindan ortak olarak, "Top-300" verilerini de kapsayan World Co-operative Monitor raporu hazırlanmaktadır. World Co-operative Monitor 2018 y1l1 raporuna göre (Anonymous, 2019d) dünya çapında en büyük 300 kooperatif, $\$ 2,1$ trilyon ABD \$ gelir yaratmaktadır. Analize konu edilen toplam 2.575 adet kooperatifin üçte biri ise tarımsal kooperatiflerdir. Bu kooperatiflerin büyük çoğunluğu (1.855 adet) Avrupa'da faaliyet göstermektedir. Kooperatiflerin sektörlere göre dağ 11 ımı Şekil 1'de verilmiştir.

Analize konu kooperatiflerin \%33'ü tarım, \%19'u bankacilık ve finans, \%16's1 diğer hizmetler, $\% 15$ 'i toptan ve perakende, \%7'si endüstri, \%6's1 kredi, \%4'ü sağlık ve eğitim ve \%1'i diğer alanlarda faaliyet göstermektedir. İșlem hacimlerine bakıldığı zaman ise tarım kooperatiflerinin ve kredi kooperatiflerinin \%33 oranla yine kooperatifler içinde en büyük paya sahip olduğu görülmektedir. Rapora (Anonymous, 2019d) göre tarım alanında gelirine göre en büyük kooperatifler $\mathrm{ABD}$, Japonya, Güney Kore, Almanya, Danimarka, Fransa, Yeni Zelenda, Hollanda, Brezilya ve İsviçre'de bulunmaktadır. Çizelge 1'de kooperatif bazında bu dağılım gösterilmektedir.

Kooperatiflerin ekonomik alanda önemli yer tuttuğu Avrupa Birliği'nde tarımsal kooperatiflerin pazar payı \%40'1 bulmaktadır (Bijman, 2016). İskandinav ülkeleri (Danimarka, Finlandiya, İsveç), İrlanda, Hollanda ve Fransa gibi ülkelerde ise bu oran \%50'nin üzerindedir.

Çizelge 1. Dünyada gelirlerine göre en büyük 10 tarımsal kooperatif (Anonymous, 2019d).

Table 1. Top 10 total turnover distributed cooperatives of the world (Anonymous, 2019d).

\begin{tabular}{rllcc}
\hline $\begin{array}{l}\text { Sira } \\
\text { Rank }\end{array}$ & $\begin{array}{l}\text { Kooperatif } \\
\text { Cooperative }\end{array}$ & $\begin{array}{l}\text { Ülke } \\
\text { Country }\end{array}$ & $\begin{array}{c}\text { Gelir } \\
\text { Milyar ABD \$) } \\
\text { Turnover } \\
\text { (Billion USA \$) }\end{array}$ & $\begin{array}{c}\text { Milli gelire oran1 (\%) } \\
\text { Ratio to GDP (\%) }\end{array}$ \\
\hline 1 & Zen-Noh & Japonya & 44,06 & 0,80 \\
2 & Nonghyup & Güney Kore & 36,45 & 2,57 \\
3 & CHS Inc. & ABD & 30,35 & 0,16 \\
4 & Bay Wa & Almanya & 17,06 & 0,49 \\
5 & Hokuren & Japonya & 14,06 & 0,28 \\
6 & Dairy Farmers of America & ABD & 13,50 & 0,07 \\
7 & Fonterra & Yeni Zelenda & 13,40 & 7,07 \\
8 & Land O'Lakes, Inc. & ABD & 13,20 & 0,07 \\
9 & FrieslandCampina & Hollanda & 12,18 & 1,56 \\
10 & Arla Food & Danimarka & 10,83 & 3,52 \\
\hline
\end{tabular}

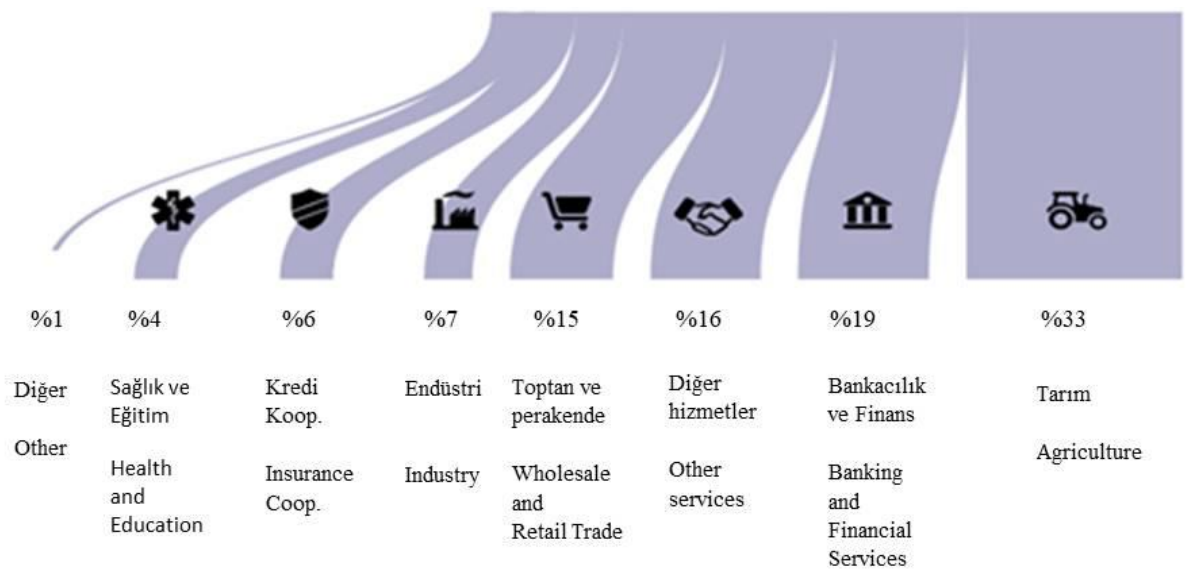

Şekil 1. Dünyada kooperatiflerin sektörel dağılımı (Anonymous, 2019d).

Figure 1. Sectoral distribution of world cooperatives (Anonymous, 2019d). 
Türkiye'de Kooperatif Ekonomisinin Mevcut Durumu

İlk uygulaması, 1863 y1lında devlet eliyle kurulan "memleket sandıkları" olan ülkemizdeki çağdaş kooperatifçiliğin, her ne kadar tabandan yapılanan bir örgütlenme modeli olmasa da Cumhuriyetin ilk yıllarından bu yana gerek örgüt sayısı gerekse üye sayısında kaydettiği artışa bakıldığında küçümsenemeyecek düzeyde olduğu görülmektedir (Sayın ve Sayın, 2004). Ticaret Bakanlığı, Aralık 2018 verilerine göre Türkiye'de 1.910 .342 adet aktif firma bulunmaktadır (Anonim, 2019c). Bu firmalardan 35.728 tanesi kooperatiftir. $\mathrm{Bu}$ kooperatiflerin yaklaşık üçte biri ise tarım alanında faaliyet gösteren kooperatiflerdir. Türkiye'de mevcutta faaliyet gösteren tarımsal kooperatif örgütlenmeleri Çizelge 2'de özetlenmiştir.

Çizelge 2'de görüldüğü üzere Türkiye'de 2019 yılı itibariyle 11.892 adet tarımsal kooperatif mevcut olup, yaklaşık 4 milyon ortak da bu kooperatiflere üyedir. $\mathrm{Bu}$ üyelerin neredeyse yarıs1 pancar ekicileri kooperatifleri üyesidir. Türkiye tarımında gerçek anlamda ilk kooperatifleşme, pancar tarımı sayesinde başlamış ve gelişim kaydetmiştir ve böylece çiftçilerin örgütlenmesinin temeli atılmıştır (Semerci, 2015). Ayrıca, İstanbul Sanayi Odası'nın her yıl yayınladığı Türkiye'nin 500 Büyük Sanayi Kuruluşu listesinde bazı kooperatifler de kendine yer bulmaktadır. 2018 yılında yayınlanan listede Konya Şeker 44., Kayseri Şeker 126., Tarım Kredi Yem 141., Trakya Yağlı Tohumlar Tarım Satış Kooperatifleri Birliği 164., Gübre T.A.Ş 206., Marmara Zeytin Tarım Satış Kooperatifleri Birliği ise 417. olarak listeye girmeyi başarmıştır (Anonim, 2019e).

Türkiye'de kooperatiflerin mevcut durumu incelendiğinde kooperatif ve üye sayılarının gelişmekte olduğu fakat istenildiği ölçüde yeterli olmadığını söylemek mümkündür. Kooperatiflerin önemli yer tuttuğu Avrupa Birliği'ndeki bazı ülkelerdeki kooperatife katılım oranları şu şekildedir; İrlanda \%70, Finlandiya \%60, Avusturya \%58. Türkiye'de ise bu oran $\% 10$ civarındadır (Çıkın, 2017).

\section{SONUÇ}

Kooperatifler, çiftçi gelirlerine ve kırsal kalkınmaya yaptıkları etkilerle, tüm dünyada ve özellikle Avrupa'da tarımsal endüstri alanında kendilerine önemli bir yer edinmişlerdir. Kooperatiflerin iktisadi öneme sahip olduğu Avrupa Birliği ülkelerinden Hollanda, bünyesinde başarılı kooperatifler barındıran bir ülke örneği olarak karşımıza çıkmaktadır. Bu ülkedeki tarımsal kooperatiflerin pazar payı yaklaş1k \%70 seviyesindedir (Bijman, 2016). Hollanda kooperatiflerinin başarısının arkasında birçok içsel ve dışsal neden bulunmaktadır. Bu nedenlerin başında kooperatiflerin nasıl yapılandırılması ve nasıl çalışması gerektiğini belirleyen öz ve etkin yasalar gelmektedir (Bijman, 2016). Yasal çerçeve, etkin üye kontrolüne olanak sağlamakta ve özellikle, milyarlarca geliri olan uluslararası şirketlere dönüşen kooperatiflerde, üye kontrolünü sağlamak ve güçlendirmek için iç yönetişimdeki yeniliklere yer açmaktadır. Literatürde, kooperatiflerdeki başarı faktörlerinden biri olarak üyelerin homojen dağılımı sıklıkla anılmaktadır. Böyle bir dağılım, demokratik karar alma mekanizmasını korur, paydaşların bağlılığını artırır ve etkin karar almaya olanak sağlar. Bir diğer başarı faktörü de kooperatifler aras1 iş birliğidir. Kooperatiflerin tarihine bakıldığında birçok başarılı kooperatif üst-örgütlenmesi görülmektedir. Ayrıca kooperatifler zaman içinde, değişen müşteri talepleri ve piyasa koşullarının gerektirdiği şekilde, maliyet liderliği stratejisinden yüksek katma-değer stratejisine uyum sağlamışlardır (Bijman, 2016). 
Çizelge 2. Türkiye tarım kooperatifleri (Anonim, 2019d).

Table 2. Agricultural cooperatives of Turkey (Anonim, 2019d).

\begin{tabular}{lcc}
\hline Türü & $\begin{array}{c}\text { Kooperatif sayıs } \\
\text { Nymber of cooperatives }\end{array}$ & $\begin{array}{c}\text { Ortak sayıs } \\
\text { Number of members }\end{array}$ \\
\hline Tarımsal kalkınma / Agricultural development & 6839 & 751.573 \\
Sulama / Irrigation & 2.443 & 298.564 \\
Su ürünleri / Aquaculture resources & 555 & 30.649 \\
Pancar ekicileri / Beet producers & 31 & 1.409 .721 \\
Tarım kredi / Agricultural credit & 1.625 & 907.233 \\
Tarım satış / Agriculture sales & 399 & 533.456 \\
Üretim pazarlama / Product marketing & 428 & 18.845 \\
Yaş meyve ve sebze / Fresh fruits and vegetables & 37 & 3.142 \\
\hline Toplam / Total & 11.892 & 3.931 .196 \\
\hline
\end{tabular}

Türkiye'de de tarımsal amaçlı kooperatifler, üye çiftçilerin ekonomik haklarını savunmak amacıyla kurulmuş örgütlerdir. Çiftçiler tüketici, üretici ya da kredi alıcısı olarak, ekonomik haklarının savunulması için çeşitli isimlerde kurulan tarım kooperatiflerine üye olmuşlardır (Mülayim, 2010). Öte yandan, Türkiye tarımsal kooperatiflerinde etkinliği ve başarıyı kısıtlayan bir takım yapısal sorunlar mevcuttur. Ortakların eğitim seviyesi, kooperatifçilik kültürü ve bilinci, birim kooperatiflerin ortak sayısı ve ölçekleri, örgütlenme ve kooperatifler arası iş birliği, sermaye ve uygun finansmana erişim, kurumsal ve profesyonel yönetim, iç ve diş denetim mekanizması ülkemiz kooperatifçiliğinde geliştirilmesi gereken öncelikli sorun alanlarıdır (Anonim, 2012). Bu doğrultuda geliştirilecek stratejiler yardımıyla, günümüz serbest piyasa koşullarına uyum sağlayabilen, çağdaş pazarlama ve lojistik teknikleri kullanan, profesyonellerce

\section{LITERATÜR LISTESI}

Anonim. 2012. T. C. Gümrük ve Ticaret Bakanlığ Kooperatifçilik Genel Müdürlüğü. Türkiye Kooperatifçilik Stratejisi ve Eylem Planı 2012-2016. Ankara.

Anonim. 2019a. Türkiye Cumhuriyeti Cumhurbaşkanlığı, Strateji ve Bütçe Başkanlığı. http://www.sbb.gov.tr/kalkinma-planlari/.

Anonim. 2019b. Kredi Garanti Fonu (KGF). https://www.kgf.com.tr/index.php/tr/.

Anonim. 2019c. T.C. Ticaret Bakanlı̆̆ https://ticaret.gov.tr/istatistikler/bakanlik-istatistikleri. yönetilen ve daha verimli üretim yapan tarımsal kooperatifler, daha uzun soluklu olarak tarım sektöründe yer almaya devam edebileceklerdir.

Kooperatifler temel olarak kırsal kesimin refah seviyesini iyileştirmede, kıt kaynaklara sahip olan üreticilerin verim ve gelirlerini artırmada ve tarımsal gelişmeyi sürdürülebilir hale getirmede önemli araçlardan biri olup, bütün dünyada etkin bir biçimde kullanılmaktadır (Semerci, 2015). Uluslararası rekabetin yoğunlaştığı bir dönemde, ülkemiz çiftçilerinin birlikte hareket etmeleri kaçınılmazdır. Sürdürülebilir tarımsal kalkınma adına temel kooperatif ilkeleri göz önünde tutularak, dünya örneklerinde olduğu üzere tarımsal kooperatif örgütlenmesinin etkin olarak kullanılması büyük önem taşımaktadır. Zira dünya tarımında ön planda olan Türkiye'nin kalkınmasında tarım, tarımın kalkınmasında da kooperatifçilik önemli rol oynayacaktır.
Anonim. 2019d. Tarımsal Örgütlenme Tablosu. https://www.tarimorman.gov.tr/TRGM/Link/33/Tarim sal-Orgutlenme-Tablosu.

Anonim. 2019e. Türkiye'nin 500 büyük sanayi kuruluşu. http://www.iso500.org.tr/.

Anonymous. 2019a. Pellervo Confederation of Finnish Cooperatives.https://www.slideshare.net/pellervo/pelle rvo-confederation-of-finnish-cooperatives.

Anonymous. 2019b. International Cooperative Alliance. https://www.ica.coop/en/cooperatives/facts-andfigures.

Anonymous. 2019c. Eurisce. https://www.euricse.eu/. 
Anonymous. 2019d. World Cooperative Monitor. Exploring The Cooperative Economy. Report 2018. https://www.ica.coop/sites/default/files/publicationfiles/wcm2018-web-1542524747.pdf .

Abebe, G. K., J. Bijman, R. Kemp, O. Omta, and A. Tsegaye. 2013. Contract farming configuration: Smallholders preferences for contract design attributes. Food Policy, Elsevier, 40 (C): 14-24.

Alkan, A. 1998. Türkiye'de 1980'den sonra dar gelirlilerin konut sorunu ve konut kooperatifleri. Türkiye Kent Kooperatifleri Merkez Birliği. Ankara.

Bernard, T., and D. J. Spielman. 2009. Reaching the rural poor through rural producer organizations? A study of agricultural marketing cooperatives in Ethiopia. Food policy, Elsevier, 34 (1): 60-69.

Bhuyan, S., and F. L. Leistritz. 2001. An examination of characteristics and determinants of success of cooperatives in the non-agricultural sectors. Journal of Cooperatives 16: 46-62. DOI: 10.22004/ag.econ.46418.

Bijman, J. 2016. Agricultural Cooperatives in the Netherlands: Key success factors. International Summit of Cooperatives.Quebec.https://www.researchgate.net/pu blication/308993047.

Bijman, J., C. Iliopoulos, K. J. Poppe, C. Gijselinckx, K. Hagedorn, M. Hanisch, G. W. J. Hendrikse, R. Kühl, P. Ollila, P. Pyykkönen, and G. van der Sangen. 2012. Support for Farmers' Cooperatives. Final Report. European Commission. Wageningen UR. https://ec.europa.eu/agriculture/sites/agriculture/files/exte rnal-studies/2012/ support -farmers-coop/fulltext_en.pdf.

Bijman, J., G. Hendrikse, and A. van Oijen. 2013. Accommodating two worlds in one organisation: changing board models in agricultural cooperatives. Managerial and Decision Economics 34 (3-5): 204-217.

Bijman, J., M. Hanisch, and G. van der Sangen. 2014. Shifting control? The changes of internal governance in agricultural cooperatives in the EU. Annals of Public and Cooperative Economics 85 (4): 641-661.

Bilgin, N. ve Ş. Tanıyıcı. 2008. Türkiye'de kooperatif ve devlet ilişkilerinin tarihi gelişimi. Karamanoğlu Mehmetbey Üniversitesi Sosyal ve Ekonomik Araştırmalar Dergisi Cilt: 2008 (2): 136-159.

Brusselaers, J., K. Poppe, and T. G. Azcarate. 2014. Do policy measures impact the position and performance of farmers' cooperatives in the EU? Annals of Public and Cooperative Economics 85 (4): 531-553.

Can, M. F. ve E. Sakarya. 2012. Dünya ve Türkiye'de tarım ve hayvanc1lık kooperatiflerinin tarihsel gelişimi, iktisadi önemi ve mevcut durumu. Veteriner Hekimler Derneği Dergisi 83 (1): 27-36.

Chaddad, F. R., and M. L. Cook. 2004. Understanding new cooperative models: an ownership-control rights typology. Applied Economic Perspectives and Policy 26 (3): 348-360.
Chaddad, F., and C. Iliopoulos. 2013. Control rights, governance, and the costs of ownership in agricultural cooperatives. Agribusiness 29 (1): 3-22.

Chloupkova, J. 2002. European Cooperative MovementBackground and Common Denominators. No 24204, Unit of Economics Working Papers from Royal Veterinary and Agricultural University, Food and Resource Economic Institute. DOI: 10.22004/ag.econ.24204.

Çıkın, A. 2017. Bir Başkadır Kooperatifçilik. İzmir: SS Tariş Zeytin ve Zeytinyağı Tarım Satış Kooperatifleri Birliği Yayını.

Dedieu, M. S., and F. Courleux. 2011. Agricultural cooperatives the reference in term of farmer economic organization. Division of Statistics and Strategic Foresight-Strategic Foresight and Evaluation Analysis 36: 1-4.

Demirtaş, E. I. ve M. Sarı. 2016. Arazi toplulaştırması. Derim 20 (1): 48-58.

Dunn, J. R. 1988. Basic cooperative principles and their relationship to selected practices. Journal of Agricultural Cooperation, National Council of Farmer Cooperatives Vol. 3: 83-93.

Fairbairn, B. 2004. History of cooperatives. pp. 23-51 In: C.D. Merrett and N. Walzer (Eds.) Cooperatives and Local Development: Theory and Applications for the 21st century. Armonk, NY \& London: M.E. Sharpe.

Fernández, E. 2014. Selling agricultural products: farmers' cooperatives in production and marketing, 18801930. Business History 56 (4): 547-568.

Fici, A. 2013. An introduction to cooperative law. International Handbook of Cooperative Law. 362. Springer, Berlin, Heidelberg.

Fischer, E., and M. Qaim. 2012. Linking smallholders to markets: determinants and impacts of farmer collective action in Kenya. World Development 40 (6): 1255-1268.

Fritz, M., and G. Schiefer. 2008. Food chain management for sustainable food system development: a European research agenda. Agribusiness: An International Journal 24 (4): 440-452.

Gutierrez, M., and A. Carlos 2005. A comparative synthesis of 20th century agricultural cooperative movements in Europe. Journal of Rural Cooperation 33: 47-65. DOI: 10.22004/ag.econ.59711.

Iliopoulos, C. 2013. Public policy support for agricultural cooperatives: an organizational economics approach. Annals of Public and Cooperative Economics 84 (3): 241-252.

Narrod, C., D. Roy, J. Okello, B. Avendaño, K. Rich, and A. Thorat. 2009. Public-private partnerships and collective action in high value fruit and vegetable supply chains. Food Policy 34 (1): 8-15. 
Mojo, D., C. Fischer, and T. Degefa. 2017. The determinants and economic impacts of membership in coffee farmer cooperatives: recent evidence from rural Ethiopia. Journal of Rural Studies 50: 84-94.

Mooney, P. H. 2004. Democratizing rural economy: Institutional friction, sustainable struggle and the cooperative movement. Rural Sociology 69 (1): 76-98.

Mülayim, Z. 1995. Kooperatif kuruluşlarda üst örgütlenmenin önemi ve Türkiye'de sorunları. Sosyal Siyaset Konferansları Dergisi 40: 33-42.

Mülayim, Z. G. 2010. Kooperatifçilik, 6. Baskı. Yetkin Yayınları.

Ostrom, E. 1990. Governing the commons: The evolution of institutions for collective action. Cambridge University Press.

Öksüz, E. 1982. Kooperatifçilik Kavramı ve İlkelerinin Işı̆ı̆ında, Türkiye'de Köy Kalkınma Kooperatifleri. Sosyal Siyaset Konferansları Dergisi 31: 329-358.

Örki, A. 2016. Ekonomik Kalkınmada Kooperatiflerin Öneminin Örneklerle Değerlendirilmesi. Optimum: Journal of Economics and Management Sciences/Ekonomi ve Yönetim Bilimleri Dergisi 3 (2).

Sauer, J., M. Gorton, and J. White. 2012. Marketing, cooperatives and price heterogeneity: Evidence from the CIS dairy sector. Agricultural Economics 43 (2): 165-177.
Sayın, B. ve C. Sayın. 2004. Türkiye'de Tarımsal Üretici Örgütlenmesi, Avrupa Birliğine uyum Hazırlıkları ve Tarımsal Üretici Birlikleri Kanunu. pp.16 -18. Türkiye VI. Tarım Ekonomisi Kongresi.

Reardon, T., C. B. Barrett, J. A. Berdegué, and J. F. Swinnen. 2009. Agrifood industry transformation and small farmers in developing countries. World Development 37 (11): 1717-1727.

Rebelo, J., J. V. Caldas, and S. C. Matulich. 2008. Manager Power, Member Behavior and Capital Structure: Portuguese Douro Wine Cooperatives. Agricultural Economics Review 9 (2): 5-15. Doi:10.22004/ag.econ.101052.

Richards, T. J., and M. R. Manfredo. 2003. Cooperative mergers and acquisitions: the role of capital constraints. Journal of Agricultural and Resource Economics 28 (1): 152-168.

Semerci, A. 2015. Türkiye'de çiftçi örgütleri: Tarımsal amaçlı kooperatifler örneği. Namık Kemal Üniversitesi, Tekirdağ Ziraat Fakültesi Dergisi 12 (1). http://hdl.handle.net/20.500.11776/1924.

Tran, N., C. Bailey, N. Wilson, and M. Phillips. 2013. Governance of global value chains in response to food safety and certification standards: the case of shrimp from Vietnam. World Development 45: 325-336. Doi: 10.1016/j.worlddev.2013.01.025.

Verhofstadt, E., and M. Maertens. 2014. Smallholder cooperatives and agricultural performance in Rwanda: do organizational differences matter? Agricultural Economics 45 (1): 39-52. 
